\title{
Repression and inactivation of $\alpha$-amylase in Thermomonospora species during growth on cellobiose
}

\author{
J. E. Busch and F. J. Stutzenberger \\ Author for correspondence: F. J. Stutzenberger. Tel: +1864656 3057. Fax: + 18646561127. \\ e-mail:SFRED@Clemson.Clemson.edu
}

Department of Microbiology, Clemson University, Clemson, SC 29631-1909, USA

\begin{abstract}
Thermophilic actinomycetes establish themselves as numerically dominant bacterial populations in selected high temperature environments by virtue of their exoenzymic ability to degrade the complex polysaccharides in thermogenic plant biomass. When Thermomonospora curvata and Thermomonospora fusca were grown on a mixture of cellulose and starch in mineral salts minimal medium, $\alpha$-amylase was repressed via inhibition of maltose uptake by cellobiose. Addition of cellobiose to exponential phase cells growing on maltose or maltotriose triggered rapid degradation of extant amylase in the culture fluid of wild-type cells, but not in a protease-deficient mutant of $T$. fusca. A serine protease purified from $T$. fusca caused inactivation of the amylase in culture fluid of the mutant when added at a concentration approximating to that of the wild-type strain. The chelating agent, EDTA, accelerated inactivation by the protease, while the presence of calcium or amylase reaction products protected the amylase. Therefore, during growth in an environment containing multiple polysaccharides, these thermophiles control the levels of their extracellular depolymerizing enzymes via both inducer exclusion and proteolytic inactivation.
\end{abstract}

Keywords: actinomycete, amylase, cellobiose, protease, Thermomonospora

\section{INTRODUCTION}

Most microbial extracellular enzymes are controlled by catabolite repression and induction via a variety of mechanisms (reviewed by Priest, 1992; Saier et al., 1996). Extracellular enzymes differ from those located in the cytoplasm because they are induced by their products rather than by substrate. Studies on inducer control have, to date, concentrated on the enterics (reviewed by Saier \& Ramseier, 1996) or on Gram-positive bacteria having low ( $<55 \mathrm{~mol} \%$ ) $\mathrm{G}+\mathrm{C}$ ratios (reviewed by Saier et al., 1995, 1996). Here we describe some aspects of inducer control over the biosynthesis of an unusual $\alpha$ amylase (Collins et al., 1993) in Thermomonospora species (thermophilic actinomycetes which have a $\mathrm{G}+\mathrm{C}$ ratio $>65 \mathrm{~mol} \%$ ). We show that this control involves competition between amylase and cellulase inducers, and also proteolytic degradation of extant amylase after the introduction of cellobiose to cultures growing on starch or its degradation products.

\section{METHODS}

Micro-organisms and culture preservation. Thermomonospora curvata strain CUB993 was isolated from municipal solid waste compost (Stutzenberger, 1971). Thermomonospora fusca strain YX was isolated and described by Bellamy (1977). T. fusca ER1, a proteinase-deficient mutant of strain YX, was derived by Wilson (1992). T. fusca YX and ER1, as well as a highly purified preparation of the strain $\mathrm{YX}$ serine proteinase (in which strain ER1 is deficient), were generous gifts from David B. Wilson, Cornell University, USA. Cultures were maintained at $-86{ }^{\circ} \mathrm{C}$ in $33 \%(\mathrm{v} / \mathrm{v})$ glycerol and added as $1 \%(\mathrm{v} / \mathrm{v})$ inoculum; cells were subcultured at least once under test conditions to remove the possibility of interference by glycerol.

Medium and growth conditions. Cultures were grown in mineral salts minimal medium (Stutzenberger, 1972a) supplemented with $0.01 \%$ yeast extract (Sigma). Carbon sources were $0.5 \%$ soluble starch (Fisher Scientific), $0.5 \%$ ground cotton fibres (surgical grade, Johnson \& Johnson), or $10 \mathrm{mM}$ maltose or maltotriose (Sigma). Carbon sources and vitamins were autoclaved as concentrated stocks and added aseptically to the salts medium after cooling. In experiments in which sugars were added to cultures during growth, the sugars were autoclaved dry in duplicate flasks into which the cultures were 
poured aseptically to avoid volume changes. All cultures (100 ml initial volume) were shaken $\left(140\right.$ r.p.m.) at $55^{\circ} \mathrm{C}$ in baffled $250 \mathrm{ml}$ Erlenmeyer flasks inclined at an angle of $30^{\circ}$ from vertical for maximal aeration. Growth was measured spectrophotometrically (Milton Roy Spectronic 1201) in a $1 \mathrm{~cm}$ light path at $610 \mathrm{~nm}$ using culture samples diluted to an $\mathrm{OD}_{610}$ of $0 \cdot 1-1 \cdot 0\left(1 \cdot 7 \mathrm{OD}_{610}\right.$ units $=1 \mathrm{mg}$ dry cell wt $\left.\mathrm{ml}^{-1}\right)$ in fresh mineral salts medium. Culture fluids used in enzyme analysis or stability studies were clarified by centrifugation for $10 \mathrm{~min}$ at $13600 \mathrm{~g}$ at room temperature.

Enzyme analyses. All enzyme activities, with the exception of proteinase, were expressed as units $=\mu \mathrm{mol}$ product released $\mathrm{min}^{-1}$. Amylase (EC 3.2.1.1) was estimated from reducing sugar liberation in $2 \mathrm{ml}$ reaction mixtures containing $2 \%$ soluble starch, $0 \cdot 1 \mathrm{M}$ MES buffer, $\mathrm{pH} 6 \cdot 0$, and $0 \cdot 1 \mathrm{ml}$ cell-free culture fluid, incubated for $10 \mathrm{~min}$ at $65^{\circ} \mathrm{C}$. Cellulase (EC $3.2 .1 .4)$ was measured as endoglucanase activity based on reducing sugar generation in $2 \mathrm{ml}$ reaction mixtures $(2 \%$ Hercules type $7 \mathrm{~L}$ CM-cellulose, $0 \cdot 1 \mathrm{M}$ MES, $\mathrm{pH} 6 \cdot 2$, and $0.1 \mathrm{ml}$ cell-free culture fluid) incubated for $10 \mathrm{~min}$ at $65^{\circ} \mathrm{C}$. Reducing sugar concentrations were measured by the dinitrosalicylic acid method of Bernfeld (1955) and expressed as glucose equivalents $\mathrm{ml}^{-1}$. Proteinase (chymotrypsin-like proteinase, EC 3.4.21.20) was measured in $0.3 \mathrm{ml}$ reaction mixtures (final $\mathrm{pH} 8.5$ ) containing equal volumes of $1.4 \%$ azoalbumin (Sigma) and cell-free culture fluid, incubated at $70{ }^{\circ} \mathrm{C}$ for $10 \mathrm{~min}$. The reaction was stopped by the addition of $1.2 \mathrm{ml} 10 \%$ trichloroacetic acid (TCA). Precipitated residual protein was removed by centrifugation $(13600 \mathrm{~g})$; $1 \mathrm{ml}$ supernatant fluid was added to $1 \mathrm{ml} 1 \mathrm{M} \mathrm{NaOH}$ and compared spectrophotometrically (1 cm light path) at $440 \mathrm{~nm}$ to corresponding blanks in which the TCA was added before culture fluid. Activity was expressed as units $=\mu \mathrm{g}$ azoalbumin hydrolysed $\mathrm{min}^{-1}$.

Proteolytic inactivation of amylase. In preliminary experiments, the serine proteinase inhibitor PMSF (Sigma) was dissolved in 2-propanol and added $\left(10^{-4}-10^{-5} \mathrm{M}\right.$ final concentration) to exponential phase cultures to measure protection of amylase from proteolysis. Control flasks received an equal volume $(0 \cdot 1 \mathrm{ml})$ of 2-propanol without PMSF.

The rates of amylase inactivation by the purified proteinase were measured at $55^{\circ} \mathrm{C}$ in T. fusca ER 1 crude cell-free culture fluid, $\mathrm{pH} 8.0$, to which was added proteinase $\left(70 \mathrm{U} \mathrm{ml}^{-1}\right.$ final concentration) purified to electrophoretic homogeneity from T. fusca YX culture fluid (Gusek \& Kinsella, 1987). Additives in some mixtures included $10 \mathrm{mM} \mathrm{CaCl}, 10 \mathrm{mM}$ EDTA or a $40 \mathrm{mM}$ (glucose equivalent) malto-oligosaccharide mixture produced from starch by $\mathrm{T}$. fusca amylase at $\mathrm{pH} 6.0,65^{\circ} \mathrm{C}$, then ultrafiltered through Amicon YM5 membranes to remove enzyme.

Measurement of soluble sugars. Uptake of maltose and other sugars by the actinomycetes was monitored as follows. Culture samples $(2 \mathrm{ml})$ were removed aseptically at intervals during growth and centrifuged for $10 \mathrm{~min}$ at $13300 \mathrm{~g}$ at room temperature. The supernatant culture fluid was filtered through $0.45 \mu \mathrm{m}$ pore size GHP13 Acrodiscs (Gelman Sciences) to remove residual particulates. Samples to be analysed for maltose in the presence of cellobiose were treated with purified $\beta$-glucosidase (type G4511, Sigma) to remove interference by cellobiose. Samples $(20 \mu l)$ were pumped by a model 314 high pressure syringe pump (Isco) at a rate of $0.67 \mathrm{ml} \mathrm{min} \mathrm{m}^{-1}$ through a RCM-Resex analytical column $\left(7.8 \times 300 \mathrm{~mm}\right.$, Phenomenex) at $85^{\circ} \mathrm{C}$ in a regulated chamber (Bio-Rad). The retention times of malto-oligosaccharides were compared to those of known standards (Sigma) by refractive index changes at $35^{\circ} \mathrm{C}$ internal cell temperature in a model
ERC-7510 detector (Erma Optical Works) linked to a CDS402 data collection system (Varian Instrument Group).

The major malto-oligosaccharides liberated from starch by the extracellular amylases of the actinomycetes were also determined. Extracellular proteins from late exponential phase $T$. curvata and $T$. fusca cultures were concentrated about 10-fold and washed free of small molecular mass components on Amicon YM5 ultrafiltration membranes with 5 vols 0.05 M MES buffer, $\mathrm{pH} 6.0$. These washed, concentrated proteins were incubated with $5 \%$ soluble starch at $\mathrm{pH} 6.0$, $65^{\circ} \mathrm{C}$, for various intervals up to $8 \mathrm{~h}$. Soluble maltooligosaccharides were collected in Centricon-10 ultrafiltration cells (Amicon) and analysed in the HPLC system described above.

Other methods. Glucose concentrations estimated by HPLC were verified by the glucose oxidase colorimetric method using the Sigma manual assay kit 510-DA. Soluble protein was determined by the dye-binding method of Bradford (1976) according to the Bio-Rad technical bulletin 8L-0275.

Statistical analysis. Coefficients of variation were calculated (AT \& T Statistical Quality Control Handbook, 1985) for assay methods by running six replicate determinations (four for HPLC methods) on representative samples. The values for amylase, growth, endoglucanase, reducing sugar, residual malto-oligosaccharides, proteolysis and soluble protein were $\pm 6 \cdot 6,14 \cdot 5,5 \cdot 6,1 \cdot 3,6 \cdot 7,2 \cdot 1$ and $3 \cdot 7 \%$, respectively. All data, except where otherwise noted, were the means of at least duplicate experiments.

\section{RESULTS}

\section{Amylase production on starch as sole carbon source}

During growth on starch as sole carbon source in mineral salts medium, the extracellular amylase levels in culture fluids of T. curvata and T. fusca reached maxima of about 17 and $7 \mathrm{U} \mathrm{ml}^{-1}$, respectively, after $2-3 \mathrm{~d}$ growth at $55^{\circ} \mathrm{C}$. The soluble malto-oligosaccharides produced from starch by the extracellular amylases of either culture were maltose and maltotriose, with trace amounts of maltotetrose and maltohexose.

\section{Amylase inactivation during growth on cellulose}

During the growth of the actinomycetes on a mixture of cellulose and starch, extracellular $\alpha$-amylase levels rose initially, but fell rapidly, compared to cultures grown on starch as sole carbon source (Fig. 1a). This result prompted a study to determine the mechanism by which the presence of cellulose caused the inactivation of amylase in culture fluid. Since cellobiose is the predominant soluble sugar which accumulates from the action of the Thermomonospora extracellular cellulases (Stutzenberger, 1972b; Aguirre et al., 1986), the disaccharide was tested for its ability to block amylase biosynthesis or to initiate inactivation of the enzyme in culture fluid. When T. curvata was grown on a mixture of maltose and cellobiose, the amylase levels in culture fluid were depressed nearly to the level of that observed during growth on glucose as sole carbon source (Fig. 1b). This depression of amylase levels in culture fluid of cells grown in a maltose/cellobiose mixture was found to be due to the ability of cellobiose to inhibit the uptake 


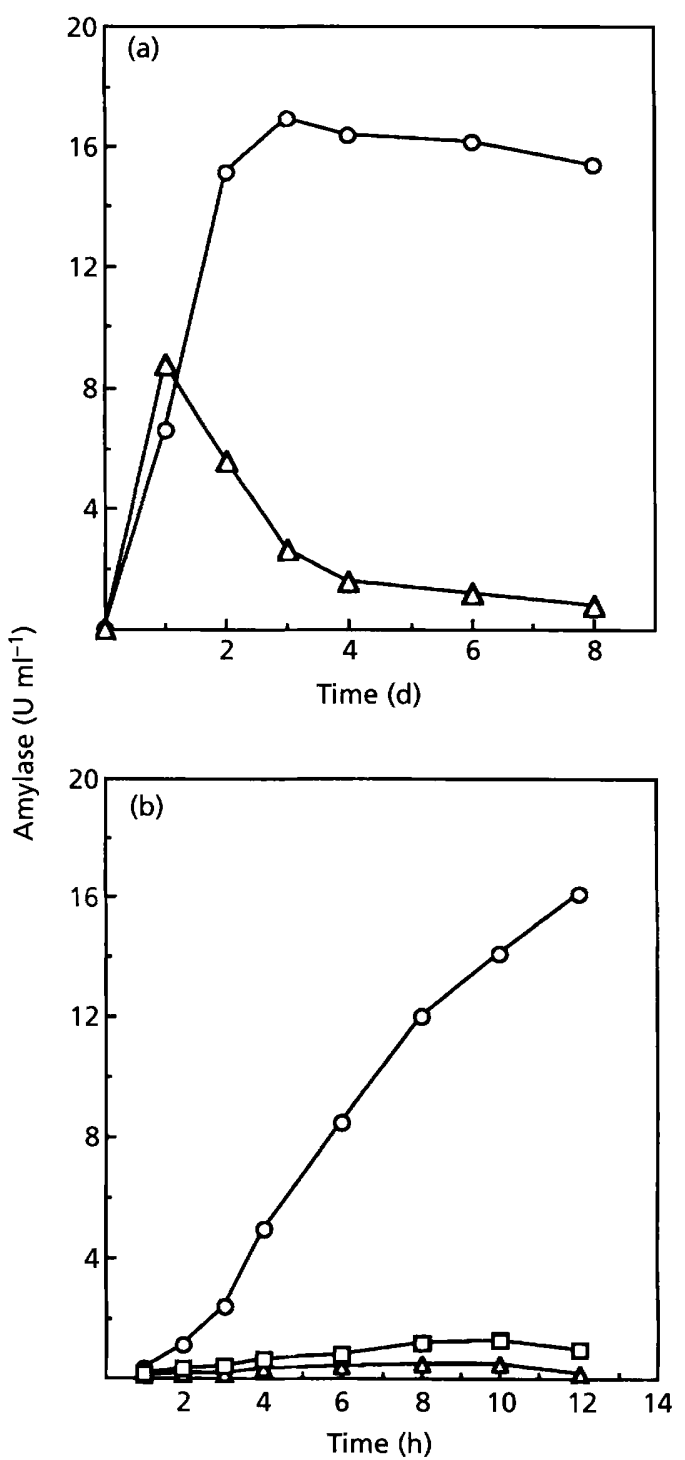

Fig. 1. Extracellular $\alpha$-amylase production by $T$. curvata during growth on various carbon sources in mineral salts minimal medium. (a) Amylase levels in culture fluid of cells grown on starch as sole carbon source $(O)$ or on a mixture of starch and cellulose $(\triangle)$. (b) Amylase in cultures grown on $10 \mathrm{mM}$ maltose (O), $10 \mathrm{mM}$ glucose $(\triangle)$ or a mixture of $10 \mathrm{mM}$ maltose and $10 \mathrm{mM}$ cellobiose $(\square)$.

of maltose from the medium; when $1 \mathrm{mM}$ cellobiose was added to a culture growing on maltose $(10 \mathrm{mM}$ initial concentration), a transient cessation of maltose uptake persisted for several hours (Fig. 2). During this time, cellobiose was taken from the medium in preference over maltose until the cellobiose concentration fell below the level of detection (detailed data not shown).

\section{Cellobiose-induced inactivation of amylase}

The ability of cellobiose to depress amylase biosynthesis in T. curvata could be explained by the inhibition of maltose uptake. However, it could not account for the

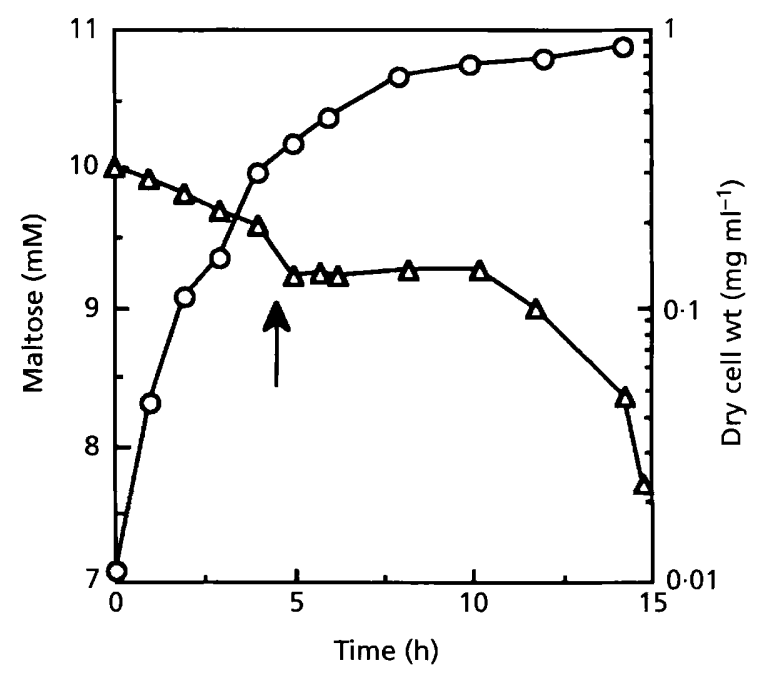

Fig. 2. Effect of $1 \mathrm{mM}$ cellobiose (time of addition shown by arrow) on maltose uptake $(\Delta)$ by $T$. curvata during growth $(O)$ in minimal medium.

rapid decrease of amylase activity in the fluid of cultures grown in the presence of cellulose. The cellulose did not bind amylase, nor did addition of cellobiose to cell-free culture fluid cause inactivation of extant amylase. Cellobiose is a cellulase inducer in Thermomonospora spp. (reviewed by Wilson, 1992), and therefore the inactivation of amylase in the presence of cellobiose was suspected to be related in some manner to cellulase induction. In T. fusca, the production of an extracellular serine proteinase has been temporally linked to cellulase biosynthesis (Gusek et al., 1988). This relationship of proteolytic activity to cellulase induction in T. fusca, and in other species (Lovrien et al., 1985), prompted studies to determine whether the cellobiose effect on extracellular amylase was due in part to proteinase activity. Our use of PMSF as a serine proteinase inhibitor in exponential phase cultures to determine its amylaseprotective effect was thwarted by its ability to inhibit growth of the actinomycetes; moreover, results were difficult to interpret because of the instability of PMSF under alkaline, high temperature culture conditions (James, 1978). Therefore, we employed a comparison of T. fusca YX and its proteinase-deficient derivative strain ER1 (Wilson, 1992; Lao \& Wilson, 1996), to evaluate the role of proteolysis in amylase inactivation.

Cellobiose introduced into a $T$. fusca culture growing on maltotriose did not cause immediate inducer exclusion of the malto-oligosaccharide as it did in the case of maltose (Fig. 3a). However, rapid induction of cellulase occurred, closely followed by peaking and decrease of amylase activity in culture fluid (Fig. 3b). Following cellobiose addition, proteinase activity of culture fluid increased about eightfold. The total protein concentration in culture fluid rose roughly in parallel with proteinase activity, so it was not apparent that the proteinase was functioning to recycle extracellular 

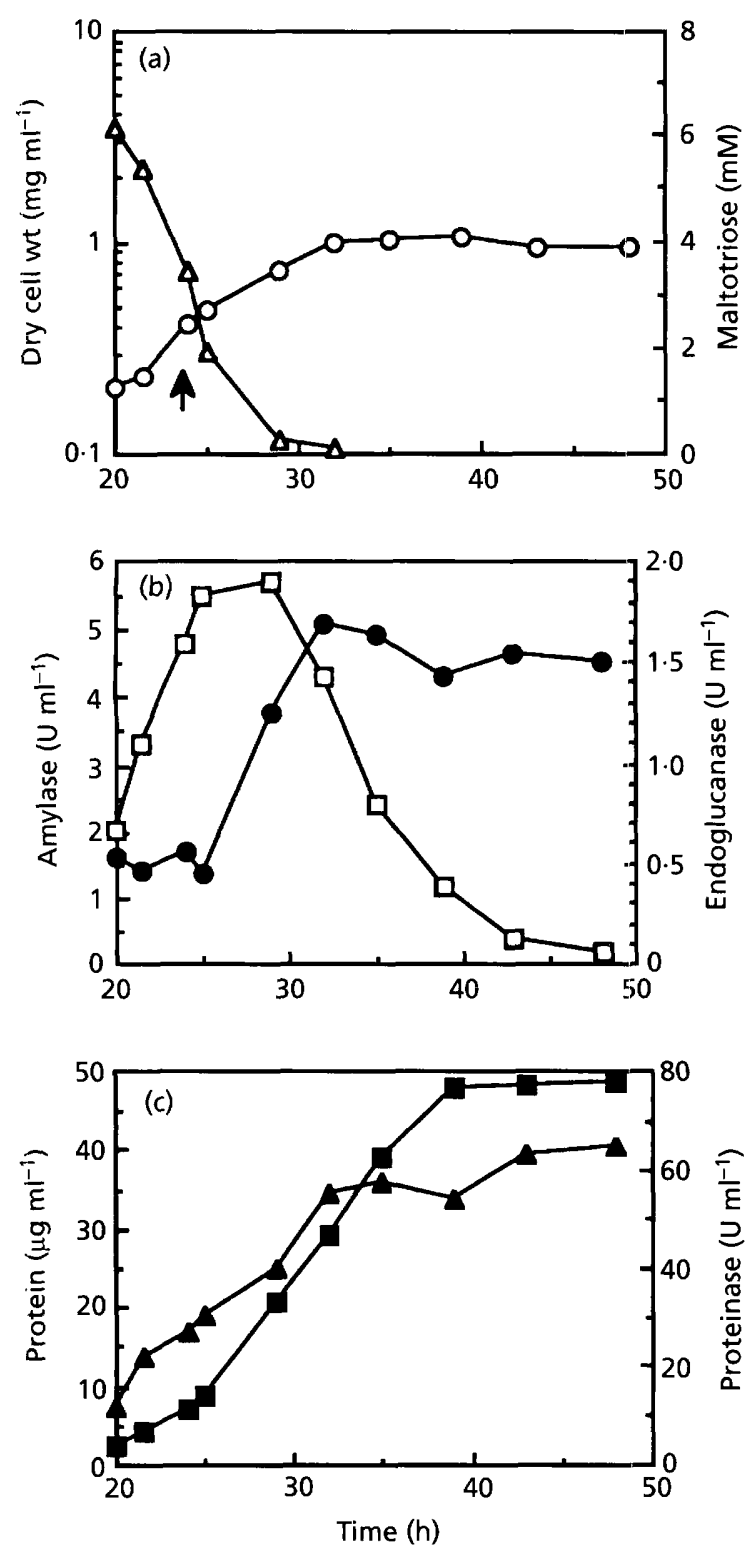

Fig. 3. Effect of $1 \mathrm{mM}$ cellobiose on $T$. fusca. (a) Growth (O) and maltotriose depletion $(\triangle)$ from fluid of culture receiving $1 \mathrm{mM}$ cellobiose (time of addition shown by arrow). (b) Amylase production and degradation $(\square)$ after induction of cellulase (measured as endoglucanase, $\mathbf{0}$ ) by cellobiose addition as shown in (a). (c) Total extracellular protein ( $\boldsymbol{\Delta}$ ) and proteinase activity $(\boldsymbol{\square})$ during cellobiose addition as shown in (a).

protein components back into the cells during the latter stages of growth (Fig. 3c).

\section{Amylase stability in proteinase-deficient culture}

The role of proteolytic activity was more clearly defined by the response of the amylase accumulation pattern to cellobiose addition in the proteinase-deficient $T$. fusca ER1. The maximal amount of amylase activity was about the same as that in T. fusca YX. However, no

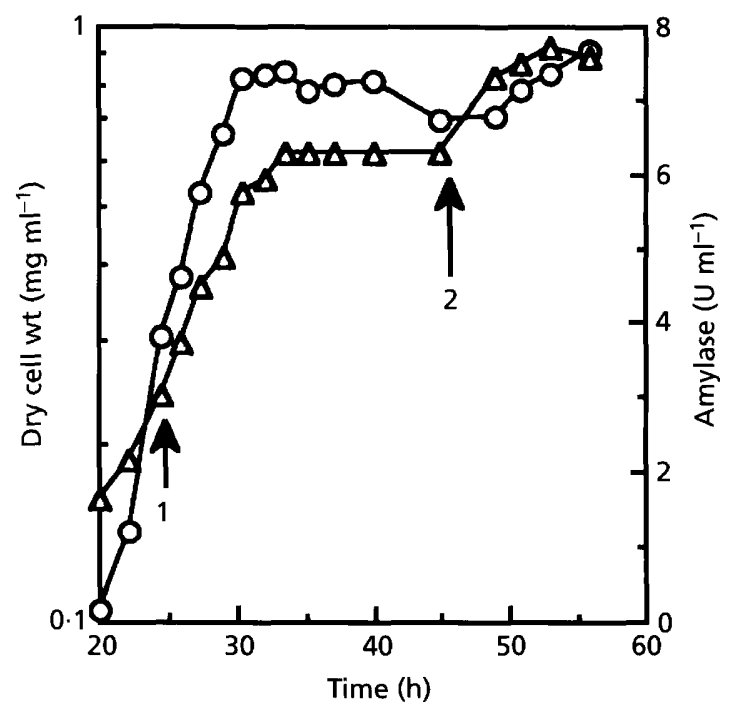

Fig. 4. Growth $(O)$ and amylase activity $(\triangle)$ in a $T$. fusca ER1 culture during addition of cellobiose (times of addition and final $\mathrm{mM}$ concentrations contributed by each addition indicated by arrows and numbers, respectively).

amylase inactivation response was observed even after repeated addition of cellobiose (Fig. 4). The uptake of the cellobiose was reflected by cellulase induction within an hour after addition of the inducer (data not shown).

\section{Amylase inactivation by purified protease}

The role of a specific serine proteinase in the degradation of amylase was confirmed by incubating the crude amylase in $T$. fusca ER1 cell-free culture fluid with proteinase purified from T. fusca YX extracellular fluid. In the absence of the proteinase, the crude amylase underwent a small amount of heat activation similar to that observed earlier for amylase in T. curvata culture fluid (Glymph \& Stutzenberger, 1977). This heat activation of the crude amylase was completely reversed by overnight incubation of the culture fluid containing the activated amylase at $5^{\circ} \mathrm{C}$. Conversely, the amylase in T. fusca ER 1 culture fluid mixed with the purified proteinase lost about $80 \%$ of its activity after incubation for $24 \mathrm{~h}$ at $55^{\circ} \mathrm{C}$ (Fig. 5). The inactivation of the amylase was increased by EDTA $(80 \%$ of activity lost within $5 \mathrm{~h}$ ), but was diminished by the presence of calcium $(20 \%$ of activity lost after $24 \mathrm{~h}$ ). In the presence of its malto-oligosaccharide reaction products, the amylase underwent a transient thermal activation (an increase in activity of about $60 \%$ relative to the control) and retained its activity over that of the zero time sample despite the presence of the proteinase.

\section{DISCUSSION}

Thermomonospora species produce a wide range of extracellular depolymerizing enzymes including amylase (Glymph \& Stutzenberger, 1977), cellulase (Calza et al., 


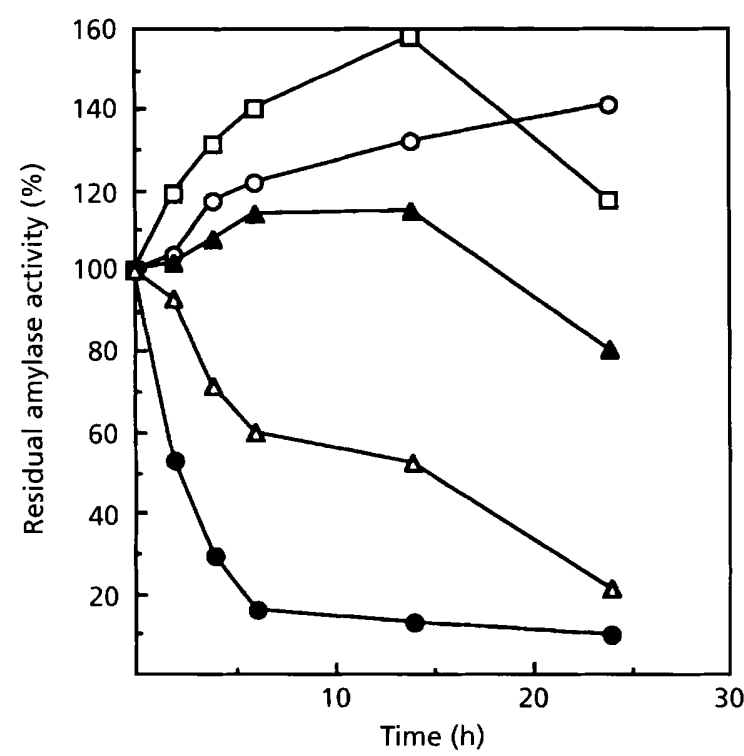

Fig. 5. Inactivation of amylase in $T$. fusca ER1 culture fluid by the serine proteinase purified from $T$. fusca $Y X$. $O$. Amylase control (no proteinase added); $\triangle$, amylase and proteinase: $\square$, amylase with proteinase in the presence of maltooligosaccharides from amylase hydrolysis of starch; $\boldsymbol{0}$, amylase with proteinase in the presence of $10 \mathrm{mM}$ EDTA; $\boldsymbol{\Lambda}$, amylase with proteinase in the presence of $10 \mathrm{mM} \mathrm{Ca}^{2+}$.

1985; Lin \& Stutzenberger, 1995), pectinase (Stutzenberger, 1987), proteinase (Gusek \& Kinsella, 1987) and xylanase (Ristroph \& Humphrey, 1985; Stutzenberger \& Bodine, 1992). Although these enzymes have all been studied as to their chemical and physical characteristics, only cellulase has received detailed attention as to the regulatory mechanisms which control its biosynthesis (reviewed by Wilson, 1992). Extracellular enzyme biosynthesis in Thermomonospora has both ecological and biotechnological implications (McCarthy et al., 1988; Trigo \& Ball, 1994), and therefore the factors which regulate their biosynthesis in these actinomycetes should be defined. This aspect would be particularly relevant during growth on a complex lignocellulosic biomass (McCarthy, 1987); the interaction and competition between inducers released concurrently from a variety of available biopolymers determine the sequence of appearance and the maximal levels attained by these enzymes (Stutzenberger \& Jenkins, 1991).

In this study, we have shown that the presence of cellulose or cellobiose blocks induction of $\alpha$-amylase via inducer exclusion and initiates inactivation of the amylase via proteolysis. The rapid decrease of $\alpha$-amylase activity when the actinomycetes were grown in the presence of cellulose does not appear to be attributable to thermal instability of the enzyme, since amylase levels were relatively constant for several days under culture conditions in the absence of cellulose, and the enzyme retains its activity at temperatures up to $65^{\circ} \mathrm{C}$ under slightly alkaline cultural conditions (Glymph \& Stutzenberger, 1977).

The cessation of amylase biosynthesis after cellulase induction would be advantageous to the actinomycetes on the basis of energy conservation, particularly since starch (which constitutes $2-6 \%$ of total polysaccharide in lignocellulosic plant material) is eliminated more rapidly than cellulose from degrading biomass (Lossin, 1970). However, the advantage of inactivation of extant amylase by proteinase is not clear. This serine proteinase, which is maximally produced during growth on cellulose (Gusek et al., 1988), alters the cellulase isozyme pattern and is capable of extensively hydrolysing the actinomycete crude extracellular proteins (Wilson, 1992). Nevertheless, Thermomonospora is not adapted for growth at the expense of proteinaceous substrates, either intact or hydrolysed (Crawford, 1975), and therefore the amylase, even after extensive proteolytic degradation, could probably not be recycled for the synthesis of new enzymes or as carbon and energy sources. Whatever functions this proteinase may serve, it does not inactivate the amylase if it is protected by its malto-oligosaccharide products and therefore would not eliminate amylase activity from the environment before the supply of starch was exhausted. This feature is consistent with the observation (Wheatley, 1987) that the predictability of the selection of enzyme proteins for degradation is greatly influenced by the presence of their substrates and co-factors.

\section{ACKNOWLEDGEMENTS}

We thank David B. Wilson for T. fusca cultures and purified protease, and Ivy Collins, La Chanda Reeves, Yolanda Richardson and Mervin Williams for technical assistance. This study was supported by the US Department of Energy through the South Carolina University Research and Education Foundation.

\section{REFERENCES}

Aguirre, M. V., Phillips, J. A., Bostwick, L. J. \& Montenecourt, B. S. (1986). Comparison of the cellulase complexes of Trichoderma reesei RL-P37 and Thermomonospora fusca YX. Chem Eng Comm 45, 93-109.

AT \& T Technologies (1985). Statistical Quality Control Handbook. Charlotte, NC: Delmar Printing Co.

Bellamy, W. D. (1977). Cellulose and lignocellulose digestion by thermophilic actinomycetes for single-cell protein production. Dev Ind Microbiol 18, 249-254.

Bernfeld, P. (1955). Amylases, alpha and beta. Methods Enzymol 1, 149-154.

Bradford, M. M. (1976). A rapid and sensitive method for the quantitation of microgram quantities of protein utilizing the principle of protein-dye binding. Anal Biochem 72, 248-254.

Calza, R. M., Irwin, D. C. \& Wilson, D. B. (1985). Purification and characterization of two $\beta$-1,4-endoglucanases from Thermomonospora fusca. Biochemistry 24, 7797-7804.

Collins, B. S., Kelly, C. T., Fogarty, W. M. \& Doyle, E. M. (1993). The high maltose-producing $\alpha$-amylase of the thermophilic 
actinomycete, Thermomonospora curvata. Appl Microbiol Biotechnol 39, 31-35.

Crawford, D. L. (1975). Cultural, morphological and physiological characteristics of Thermomonospora fusca (strain 190Th). Can J Microbiol 21, 1842-1848.

Glymph, J. L. \& Stutzenberger, F. J. (1977). Production, purification and characterization of $\alpha$-amylase from Thermomonospora curvata. Appl Environ Microbiol 34, 391-397.

Gusek, T. W. \& Kinsella, J. E. (1987). Purification and characterization of the heat-stable serine proteinase from Thermomonospora fusca YX. Biochem J 246, 511-517.

Gusek, T. W., Wilson, D. B. \& Kinsella, J. E. (1988). Influence of carbon source on production of a heat stable protease from Thermomonospora fusca YX. Appl Microbiol Biotechnol 28, 80-84.

James, G. T. (1978). Inactivation of the protease inhibitor phenylmethylsulfonyl fluoride in buffers. Anal Biochem 86, 574-579.

Lao, G. \& Wilson, D. B. (1996). Cloning, sequence and expression of a Thermomonospora fusca protease gene in Streptomyces lividans. Appl Environ Microbiol 62, 4256-4259.

Lin, S.-B. \& Stutzenberger, F. J. (1995). Purification and characterization of the major $\beta$-1,4-endoglucanase from Thermomonospora curvata. J Appl Bacteriol 79, 447-453.

Lossin, R. D. (1970). Compost studies: part I. Compost Sci 11, 16-17.

Lovrien, R. E., Gusek, T. \& Hart, B. (1985). Cellulase and protease specific activities of commercially available cellulase preparations. J Appl Biochem 7, 258-272.

McCarthy, A. J. (1987). Lignocellulose-degrading actinomycetes. FEMS Microbiol Rev 46, 145-163.

McCarthy, A. J., Ball, A. S. \& Bachmann, S. L. (1988). Ecological and biotechnological implications of lignocellulose degradation by actinomycetes. In Biology of Actinomycetes '88, pp. 283-287. Edited by Y. Okami, T. Beppu \& H. Ogawara. Tokyo: Scientific Societies Press.

Priest, F. G. (1992). Enzymes, extracellular. In Encyclopedia of Microbiology, Vol. 2, pp. 81-93. Edited by J. Lederberg. San Diego: Academic Press.

Ristroph, D. L. \& Humphrey, A. E. (1985). Kinetic characterization of the extracellular xylanases of Thermomonospora sp. Biotechnol Bioeng 27, 832-836.

Saier, M. H. \& Ramseier, T. M. (1996). The catabolite repressor/ activator (Cra) protein of enteric bacteria. J Bacteriol 178, 3411-3417.

Saier, M. H., Jr, Chauvaux, S., Deutscher, J., Reizer, J. \& Ye, J.-J. (1995). Protein phosphorylation and the regulation of carbon metabolism: comparisons in Gram-negative versus Gram-positive bacteria. Trends Biochem Sci 20, 267-271.

Saier, M. H., Jr, Chauvaux, S., Cook, G. M., Deutscher, J., Paulsen, I. T., Reizer, J. \& Ye, J.-J. (1996). Catabolite repression and inducer control in Gram-positive bacteria. Microbiology 142, 217-230.

Stutzenberger, F. J. (1971). Cellulase production by Thermomonospora curvata isolated from municipal solid waste compost. Appl Microbiol 22, 147-152.

Stutzenberger, F. J. (1972a). Cellulolytic activity of Thermomonospora curvata: nutritional requirements for cellulase production. Appl Microbiol 24, 77-82.

Stutzenberger, F. J. (1972b). Cellulolytic activity of Thermomonospora curvata: optimal assay conditions, partial purification and product of the cellulase. Appl Microbiol 24, 83-90.

Stutzenberger, F. J. (1987). Inducible thermoalkalophilic polygalacturonate lyase from Thermomonospora fusca. J Bacteriol 169, 2774-2780.

Stutzenberger, F. J. \& Bodine, A. B. (1992). Xylanase production by Thermomonospora curvata. J Appl Bacteriol 72, 504-511.

Stutzenberger, F. J. \& Jenkins, T. (1991). Temperature dependent patterns of enzyme biosynthesis in Thermomonospora curvata. World J Microbiol Biotechnol 7, 526-532.

Trigo, C. \& Ball, A. S. (1994). Is the solubilized product from the degradation of lignocellulose by actinomycetes a precursor of humic substances? Microbiology 140, 3145-3152.

Wheatley, D. N. (1987). Predictability of the 'selection' of proteins for degradation: further comments. Microbios Lett 36, 77-84.

Wilson, D. B. (1992). Biochemistry and genetics of actinomycete cellulases. Crit Rev Biotechnol 12, 45-63.

Received 7 August 1996; revised 17 January 1997; accepted 12 February 1997. 